was much the most serious contingency. During the the operation the brain was not handled, all the manipalations being on the tumour, the flat surface of the periosteal elevator alone coming in contact with the brain. The instruments and sponges were kept in a 1 in 40 carbolic lotion. There was very little sponging, and all things were kept as dry as possible. There was never any free lotion in the wound. The dura mater having been removed on account of its attachment to the tumour, the pieces of bone were not replaced; a permanent opening is thus left in the skull, measuring two inches and three-quarters by two inches and a quarter.

Description of the tumour. - The appearance presented by the trmour is well shown in the two plates, which represent the actaal size of the growth. It measured 3 in. in length, $2 \mathrm{in}$, in breadth, and $1 \frac{1}{4}$ in. in depth. On microscopical examination the tumour proved to be a sarcoma.

After.progress.-The progress of the patient after operation was in every way most satisfactory. The temperature only once reached $100^{\circ}$ forty-eight hours after the operation ; on four other occasions only did it rise above $99^{\circ}$. After the first forty-eight hours the pulse ranged between 72 and 88 . As an immediate result of the operation the vomiting and the noises in the head ceased, the pain in the head was relieved, and the irritability of temper disappeared. With the exception of the night after the operation, when sleep was broken, the patient slept about eight hours each night. F or the first twelve days the wound was dressed daily on account of the large amount of cerebro-spinal fluid which saturated the dressings. On the third day the gauze plug was removed. This was not accompanied by any hæmorrhage, but a small fusiform piece of brain substance, one inch in length and a quarter of an inch in diameter, came away with it. On the fourth day the entire scalp and face were very much swollen and cedematous, especially on the left side, on which the patient had been lying. This swelling, which continued daring the fifth day and gradually subsided on the sixth without having produced any ill-effects, appeared to be entirely due to extravasation of cerebro-spinal fluid into the sub. cataneous tissues. The wound anited by first intention with the exception of the small opening, through which the cerebrospinal lluid continued to leak for about three weeks. There was profuse diaresis during the whole of the third week. For five days six pints of urine were passed in the twenty-four hours. On the sixth and seventh days of the third week nine and a half pints of nrine were passed. The urine was clear and did not contain either sugar or albumen. The muscles of the left arm and leg rapidly regained power in the following order On Jaly 3rd there was already some increase in the power of the extensors and flexors of the forearm. The patient could extend and invert the left foot and flex the great toe to a very slight extent. On waking on the morning of the 7th the patient stretched himself, and the nurse noticed that he stretched out the left arm as well as the right, and also extended the fingers of the left hand, movements which he was quite unable to execute voluntarily while fully a wake. 0 a the 9 ch the power of flexion and inversion of the left foot and of flexion of the great toe had increased. The associated morements of the left arm occurred each morning when the patient stretched on waking. On the 12th he got out of bed and walked across the room. In doing so he was able to carry the left leg forward more strongly than before the operation. $0 n$ the 17 th the patient could abduct and raise the left arm a little. In the erect position he could fally flex the elbow, and the rigidity of the biceps had diminished. There was a distinct increase in power in both the Hexors and extensors of the hip-joint and of the knee-joint. When lying on his back he conld flex and invert his foot and flex the toes to a slight extent. In walking the left foot was no longer dragged, but was carried forward with a semicircular sweep, and when planted showed a tendency to assume a position of slight equino-varus, with the toes spread out. The reflexes had not changed in character since the operation. On the 20th the fingers were voluntarily flexed for the first time. On the $28 \mathrm{th}$ there was considerable power of flexion in the left thumb and index finger. He could walk about the house without any support. On the 30th the thumb and all the fingers of the left hand could be feebly extended. On Aug. 1st the left wrist conld be slightly extended. On the 10th the wrist and fingers could be fully flexed and extended and a stick could be grasped in the left hand. The optic neuritis had very much diminished since the removal of the tamour. On the 13th the hand could be pronated and supinated. On Sept. 3rd all the muscles of the left upper limb could be made to contract voluntarily and all movements executed, though much less strongly than on the right. He could walk two miles with the help of a stick. On Oct. 10th the patient felt well. There was no headache, pain, or noise in the head. He slept and ate well, and his general health was excellent. He could walk as many as five miles with the help of a stick. He could use the left arm for many purposes. He could touch the back of his head, take off his cap, and use a fork with the left hand. There was, however, some rigidity of the muscles of the arm. The muscular sense was still deficient, but not to such an extent as it was three months before. He still walked with a limp, but could advance the left foot fairly well, and there was less circumduction than there had been. The reflexes remained just as they were before the operation. Only slight traces of the optic neuritis could now be seen. There was slight bulging of the scalp over the site of the tumour, but now that the hair had grown ag in this showed but little.

Remarks.-The improvement which had taken place in the condition of the patient within three months of the removal of the tumour was very considerable. From being unable to lift the arm or walk further than across the room, the patient could use the arm for many purposes and walk five miles without fatigue. The headache, vomiting, and noises in the head were removed at once by the operation. The optic neuritis steadily subsided after it. The after-progress was as straightforward as it usually is after quite a minor operation. The treatment was carried out in an ordinary bedronm, and, except at the operation itself, without the aid of skilled nursing. The improvement has been fully maintained, and the patient is now (March 5th, 1895) in excellent general health. He says that he can walk "any distance." The grasp of the hand is as strong on the left as on the right side. Newcastle-on-Tyne.

\section{CASE OF A GIRL SAID TO HAVE BEEN MIRACULOUSLY CURED OF PARALYSIS AT ST. WINEERIDE'S WELL, NORTH WALES.}

By THOMAS OLIVER, M.D.GLASG., F.R.C.P. LOND, PHISICIAN TO THE ROYAT INFIRMARY, NEWCASTLE-UPON-TYNE.

The publicity given in the daily and weekly press to the. "miraculous cures" that have been effected at Holywell, the pictorial representations of St. Winefride's Well in several of the illustrated papers, and the fact that for several weeks past I have been the recipient of letters of inquiry from various parts of England, most of them hitherto unanswered, must be my excuse for placing in THE LANCET the medical facts of a case already encircled by the halo of romance and round which is being thrown an air of mystery. For some time past Holywell has been the resort of an increasing number of invalids, each hoping by immersion to be suddenly relieved of his or her infirmity. If the stories of the " miraculous cures" thereat accomplished can be accredited the Well of St. Winefride bids fair to rival Lourdes, whose grotto is now world-known, and of which and the hordes of human wrecks that besiege it Zola has given us a marvellously realistic delineation. Holywell claims its cures not less traly' though less pretentiously than the little French town that: nestles in the Pyrenees ; and, as one of the recent cures that. have taken place at Holywell concerns a patient who was formerly under my care in the Newcastle Infirmary, I shall briefly state the history of her case before her visit to the Well of St. Winefride and since her retarn from it, simply introducing here and there relevant facts that have been supplied to me by the patient or the mother, who accom=. panied her to North Wales.

The patient, a young woman aged seventeen years, was admitted to the Royal Infirmary, Newcastle-upon-Tyne, on April 28th, 1894, complaining of curvature of the spine, pain in the legs and of difficulty in walking, pains in the head, and occasional dimness of sight. Her father died fifteen years ago from typhoid fever; her mother is still living and healthy. She has five brothers and one sister, all of whom are rather delicate. At the age of eleven patient left school, but owing to ill-health did nothing until 
she was fourteen years of age, when she entered domestic service, leaving it a year afterwards on account of sorethroat. She began to menstruate at the age of sixteen and has been regular. The patient stated that her spine had been bent as long as she could remember, and that she has always walked with her head fixed and thrown a little forward. During June, 1893, she had left-sided pleurisy without effusion, and was in bed for a month with it. On recovering she noticed that she walked more bent than formerly, and that she had pain in the head and neck; but it was not until eight months after this that the pain affected her legs and knees. The pain is described as having been constant and more of an aching character, aggravated by walking or if the limbs were touched. Her condition on admission was as follows. Alimentary system : the lips were normal and the teeth fairly good; the tongue was large, pale, and coated with white fur. She had some dysphagia owing to enlarged tonsils. The palate was highly arched, which caused the patient to speak rather indistinctly. Her appetite was poor and the bowels were constipated. Circulatory system : the pulse was 84 and feeble; the heart sounds were normal; the lungs were healthy; the pupils were fully dilated and equal ; they reacted to light and accommodation. Nervous system : there was slight angular curvature of the spine, most pronounced in the dorsal region. There was marked hyperæsthesia on touching the skin over the spine, and on percussing it pain was felt particularly in the lower dorsal region. On pressing the head down towards the spine pain was felt in the cervical region. On pricking the sole of the left foot with a pin no pain was experienced at all, but there was hyperæsthesia of the right sole. Sensation was normal in the front of both legs. Ankle clonus was present. The knee-jerk was normal on engaging the patient's attention. On asking her to walk it was noticed that the head was thrown forward and that she somewhat dragged the left foot. On May 5th, 1894, the borders of the optic disc were even and the retina was healthy. There were still analgesia of the left foot and excessive knee-jerk in both legs. As the case was regarded as neurotic or one of a functional character in a girl the subject of a slightly curved spine of old standing and unaccompanied by any symptoms of increasing cord pressure, it was not considered necessary to retain her as an in-patient in the infirmary. Here it may be stated that prior to coming under my care the patient had been treated by one of $m y$ surgical colleagues, who regarded the case as one of hysterical spine.

I saw nothing more of the girl until, receiving several letters in regard to her "miraculous cure" at Holywell, I wrote to the mother asking that her daughter might be brought to me at the infirmary for examination. This was done on Feb. 7th of this year, and the following statement was supplied to me by the mother. In November, 1894, her daughter was lying in bed a perfect cripple. She was quite unable to stand. She had not been out of bed for seven months, hence the fact of her not appearing at my outpatient department at the infirmary. Mr. Galbraith of Grosforth had attended ber from time to time. Owing to informa. tion of a friend in the county of Durham "having been miraculously cured of lameness at Holywell," it was arranged that the patient in question should visit the sacred well. Accordingly, in the early morning of Nov. 27th she was dressed, lifted from bed, and taken by a cab to the railway station, placed in the recumbent position in a third-class railway carriage, and conveyed to North Wales, reaching Holywell station in the evening of the same day. Thence she was carried by the porters to an omnibus and thus driven to the hospice, a distance of one mile and a half. The huspice is stated to be a receiving home for Roman Catholic patients visiting Holy well, and is superintended by two nuns. It is not, however, confined exclusively to Roman Catholics. Protestants are equally admitted, provided they give some indications of their faith in the virtues of the water. The patient was one of sereral inmates, male and female, and at ten o'clock on the morning following her arrival at the hospice she was wheeled to St. Winefride's Well, where she was stripped. She put on a bathing dress and was carried by her mother and another woman who was staying at the hospice into the well. Shortly after her immersion the patient is stated to have fainted, but in spite of this she was retained in the water. There was no religious service going on at the wellside, nor had there been any special service that morning at the hospice before leaving-nothing but the ordinary service, which, however, the patient had not attended. The patient, I may remark, is a Roman
Catholic. It appears that after the immersion no immediate effect was noticed. She was therefore wheeled back to the hospice and placed in a chair in the general ward. After sitting in a bent position for an hour the mother states that her daughter sat upright, and maintained this position more or less all that day, but made no attempt to walk. Next morning at the same hour the patient was wheeled to St. Winefride's Well and again immersed. After a few moments she is said to have mored both legs, and to have raised herself up the steps out of the well. She subsequently walked back to the hospice- a distance of about half a mile-supported between her mother and another woman. On the day succeeding this the patient walked to the well in company with, and supported by, the same two friends, and was again immersed. When in the water she is credited with having said, "Mother, what a queer sensation; there is a burning heat in my back." To which the mother responded, "Ob Hannab, pray, you are going to be cured." The patient immediately afterwards walked out of the well to the dressing-room, where "steam was noticed rising from her body," and a feeling of tingling and heat complained of in her spine, and the mother on examining the back uttered, "Oh, Hannah, your bones have gone in." She walked back to the hospice, where she was examined by a medical man, who pronounced her a marvellous cure. That evening she walked to the town and for the next three days strolled about. Exactly one week after their admission the patient and her mother left the hospice, the daughter sitting bolt upright in the omnibus. To the surprise of the porters at Holywell station she walked into the train. She reached home on the evening of Dec. 4th, walking at the end of her long journey from the tramway terminus to $\mathrm{C}_{0 \mathrm{x}}$. lodge, a distance of nearly a mile. Her condition on Feb. 7th 1895, was as follows. There was still slight inclination of the head to the right, causing an apparent shortening of the right side of the neck. There was also slight lateral curva. ture of the spine in the dorsal region, the inclination being to the right, with distinct prominence of the two lower dorsal spines. No pain was complained of on percussing the spine. On bending it was noticed that the column moved en masse, with a tendency for the body to be deflected to the left. There was slight hyperæsthesia of the skin of the back, the prick of a pin and the application of the blunt point of a pencil being evidently followed by exaggerated impressions. The kneejerks were excessive; there was slight ankle clonus. The patient walked remarkably well and was evidently proud of being able to do so. There was no halting or dragging of the limbs. When walking it was noticed that her head was thrown forwards and with a distinct inclination to the righ side. She still wore a poroplastic jacket which was supplied to her in the early part of 1894 , and on the recommendation of the medical practitioner who saw her at Holywell was going to wear it all the winter. Her heart and lungs were healthy. Menstruation was regular.

These, then, are briefly the medical facts of the case. A girl who was recognised by myself in April, 1894, as a neurotic, with slight spinal curvature but without evidence of increasing pressure on the cord, and by one of $m y$ colleagues at the infirmary as suffering from hysterical spine, subsequently developed paralysis of the lower extremities, which lasted for six months. There is no need to doubt the paralysis any more than there is to question her present ability to walk. The patient left home in November for Holywell strongly buoyed up with hope and with great ezpectations in regard to her recovery, having received the Holy Communion in bed on the day before starting. The charge at the hospice is $7 \mathrm{~s}$. a week for each inmate. This, with the railway and other incidental expenses, made it absolutely necessary, as the family belonged to the labouring classes, that the visit to North Wales should not be unduly prolonged. It is difficult to appraise at its proper value the effects of immersion of the whole body in an exposed well of cold water in the early morning of a November day upon one unaccustomed to such a proceeding but at any rate they must be considerable. What want of will cansed and what strength of will failed to accomplish in our patient strong physical and mental impressions overcame It is not the first time that cold water suddenly applied to the external surface-over a large area and nearer home than Holywell-has roused up dormant nerve energies and been followed by results as satisfactory and permanent as the cure of the patient in question "miraculously" accomplished by dipping in the Well of St. Winefride.

Newcastle-upon-Tyne. 